\title{
New Quantitative Trait Loci in Wheat for Flag Leaf Resistance to Stagonospora nodorum Blotch
}

\author{
M. G. Francki, M. Shankar, E. Walker, R. Loughman, H. Golzar, and H. Ohm
}

First, second, third, fourth, and fifth authors: Department of Agriculture and Food Western Australia, 3 Baron Hay Ct, South Perth, Western Australia, Australia; sixth author: Department of Agronomy, Purdue University, West Lafayette, IN 47907.

Current addresses of M. G. Francki and E. Walker: State Agricultural Biotechnology Centre, Murdoch University, Murdoch, Western Australia, 6150, Australia.

Accepted for publication 26 June 2011.

\begin{abstract}
Francki, M. G., Shankar, M., Walker, E., Loughman, R., Golzar, H., and Ohm, H. 2011. New quantitative trait loci in wheat for flag leaf resistance to Stagonospora nodorum blotch. Phytopathology 101:1278-1284.

Stagonospora nodorum blotch (SNB) is a significant disease in some wheat-growing regions of the world. Resistance in wheat to Stagonospora nodorum is complex, whereby genes for seedling, flag leaf, and glume resistance are independent. The aims of this study were to identify alternative genes for flag leaf resistance, to compare and contrast with known quantitative trait loci (QTL) for SNB resistance, and to determine the potential role of host-specific toxins for SNB QTL. Novel QTL for

wheat parent 'EGA Blanco'. The chromosomal map position of markers associated with QTL on 1BS and 2AS indicated that they were unlikely to be associated with known host-toxin insensitivity loci. A QTL on chromosome 5BL inherited from EGA Blanco had highly significant association with markers $f_{c p} 001$ and $f_{c p} 620$ based on disease evaluation in 2007 and, therefore, is likely to be associated with Tsn1-ToxA insensitivity for flag leaf resistance. However, $f c p 001$ and $f c p 620$ were not associated with a QTL detected based on disease evaluation in 2008, indicating two linked QTL for flag leaf resistance with multiple genes residing on 5BL. This study identified novel QTL and their effects in controlling flag leaf SNB resistance.
\end{abstract} flag leaf resistance were identified on chromosome 2AS inherited from winter wheat parent 'P92201D5' and chromosome 1BS from spring

Necrotrophic fungal pathogens play a significant role in disease of wheat worldwide. Phaeosphaeria nodorum (E. Müll.) Hedjar., anamorph Stagonospora nodorum (Berk.) E. Castell. \& Germano (= syn. Septoria nodorum (Berk) Berk.) causes Stagonospora nodorum blotch (SNB) disease on leaves and glumes. In Australia, SNB contributed average annual wheat yield losses of $12.9 \%$ in the Western region in the first decade of the 21 st century (19). Therefore, breeding resistant cultivars could significantly reduce yield losses during disease epidemics.

An in-depth understanding of the genetics of host-pathogen interactions provides much needed information for efficiently deploying resistance genes in commercial wheat cultivars. The genetics of host resistance to $S$. nodorum in seedling and adult plants is complex. Polygenic inheritance with minor effects and interacting in a additive, dominance, or epistatic manner has been reported for seedling resistance $(9,18,24,31)$, whereas adult plant resistance is similarly inherited but controlled by independent genes for flag leaf and glume resistance $(6,12,20,23,30)$. The reduced number of lesions in seedlings does not unequivocally correlate with field resistance or tolerance $(23,27)$, and it is not often possible or practical to predict SNB reaction in adult plants based on seedling tests (5). Therefore, breeding effective resistance to SNB relies on combining multiple genes and selecting progeny for specific and independent resistance in flag leaf, glume, and seedling $(6,24)$.

Identification of molecular markers linked to quantitative trait loci (QTL) is becoming increasingly important to track SNB

Corresponding author: M. G. Francki;

E-mail address: michael.francki@agric.wa.gov.au

doi:10.1094/PHYTO-02-11-0054

(c) 2011 The American Phytopathological Society
Additional keywords: DArT, Phaeosphaeria nodorum, pleiotropy, SSR.

resistance genes. A number of QTL for seedling resistance have been identified using biparental mapping populations as residing on wheat chromosomes $1 \mathrm{~B}, 2 \mathrm{~B}, 2 \mathrm{D}, 4 \mathrm{~B}, 5 \mathrm{~A}, 5 \mathrm{~B}, 5 \mathrm{D}$, and $6 \mathrm{~A}$ $(1,4,8,14,17,22)$. QTL for seedling resistance on chromosomes $6 \mathrm{~A}$ and 7A were recently identified in association mapping studies (2). QTL for flag leaf resistance were identified on chromosomes 1B, 2A, 2D, 5A, 5B, and 7A $(3,13,27)$ and glume resistance on $2 \mathrm{D}, 3 \mathrm{~B}, 4 \mathrm{~B}$, and $5 \mathrm{~A}(3,25,27,28)$. The majority of QTL for seedling, flag leaf, and glume resistance from these studies contributed a small proportion (usually $<20 \%$ ) of phenotypic variation. In some instances, QTL on similar chromosomal positions in separate studies indicated different genes or alleles contributing to seedling and adult plant resistance $(17,25,27)$.

Studies have provided evidence that host-specific toxins SnTox2 and SnToxA are secreted from Stagonospora nodorum and corresponding host sensitivity QTL reside on wheat chromosomes 2DS (Snn2) and 5BL $(T s n 1)$, respectively $(16,17)$. Both Snn2 and Tsn1 co-locate with a QTL for flag leaf resistance from a Brazilian genotype, BR34, indicating a role for toxin-host interactions. In other studies, however, QTL for flag leaf and glume resistance were not associated with any known loci for toxin insensitivity $(25,27,28)$, indicating that either different genes or alleles control toxin insensitivity or mechanisms different from the compatible toxin-host interactions are responsible for adult plant resistance in spring and winter wheat accessions.

SNB is prominent in high-rainfall regions and is most damaging in warm, moist conditions at the time when plants reach physiological maturity. Therefore, there is a greater emphasis on developing flag leaf and glume resistance in commercial cultivars. Two QTL for glume resistance on chromosomes 2D and 4B have shown to be effective in Western Australian environments $(27,28)$ and are suitable for deploying in genetic backgrounds. However, only one QTL for flag leaf resistance has been identified on 
chromosome 2D in spring wheat (27). Therefore, it is important to identify alternative QTL to increase genetic gain for flag leaf resistance to SNB in Western Australian environments. The aim of this study is to identify alternative genes for flag leaf resistance, to compare and contrast with known QTL for SNB resistance, and to determine the potential role of host-specific toxins for SNB QTL. The study focuses on a winter wheat recombinant inbred (RI) line population and a spring wheat doubled-haploid mapping population, whereby winter wheat breeding line 'P92201D5' and spring wheat 'EGA Blanco' are parents in two populations, respectively, and both have moderate levels of flag leaf resistance effective in Western Australian environments.

\section{MATERIALS AND METHODS}

Plant material and homozygous populations. Parents were chosen because of their suitable disease reaction and also having the Rhtl allele to avoid major plant height segregation in the homozygous populations. Parental winter wheat genotypes 'P92201D5' and 'P91193D1', were obtained from the wheat breeding program collection at Purdue University, West Lafayette, IN. An RI population denoted as 'P9819RB1' was developed at Purdue University by single-seed descent from a random population of $254 \mathrm{~F}_{2}$ plants from a cross of the two parental winter wheat lines, P92291D5 and P91193D1 (28). The spring wheat EGA Blanco and 'Millewa' were obtained from the collection at the Department of Agriculture and Food Western Australia. The spring wheat doubled-haploid (DH) population, '05Y001', consisted of 235 individuals developed from an $F_{1}$ cross of parental genotypes (11).

Genetic map development. P9819RB1 and 05Y001 populations were used to generate high-resolution genetic linkage maps consisting of simple-sequence repeat (SSR) and diversity array technology (DArT) markers. Details of genetic marker linkage map construction are reported by Francki et al. (11). Briefly, P9819RB1 consisted of 385 markers distributed on all 21 chromosomes with an average distance of 7.8 centimorgans $(\mathrm{cM})$ between markers and total coverage of 3,013 cM. Similarly, a genetic map for the 05Y001 population consisted of 468 SSR and DArT markers, with an average resolution of $6.5 \mathrm{cM}$ between markers and a genome coverage of $3,058 \mathrm{cM}$. Additional markers fcp001 and fcp620 described by Zhang et al (34) were mapped to chromosome 5BL in the $05 Y 001$ population.

Flag leaf phenotyping. Populations were sown in an irrigated field nursery at South Perth, Western Australia in 2004 and 2005 for the P9819RB1 population and 2007 and 2008 for the 05 Y001 population. Prior to sowing, individuals of the P9819RB1 population and parents were germinated on petri dishes for $24 \mathrm{~h}$ and vernalized for 7 to 9 weeks at $2^{\circ} \mathrm{C}$ with $8 \mathrm{~h}$ of light per day before transplanting in the field. There were three replications each in randomized split block design and sown as paired $10-\mathrm{cm}$ rows of up to 15 seeds per row sown $10 \mathrm{~cm}$ apart and separated by $35 \mathrm{~cm}$ of adjacent rows. Plots were fertilized with superphosphate, urea, and potash and protected from powdery mildew infection with Quinoxyfen at $250 \mathrm{~g} / \mathrm{ha}$ and Bupirimate at $125 \mathrm{~g} / \mathrm{ha}$ applied 2 weeks after sowing and at 4 weekly intervals for 12 weeks.

Flag leaves of individual plots were sprayed with a conidial suspension $\left(10^{6}\right.$ conidia/ml with $0.5 \%$ gelatine $)$ of a mixture of 10 isolates of $S$. nodorum (WAC13068, WAC13069, WAC13070, WAC13071, WAC13072, WAC13073, WAC13074, WAC13075, WAC13076, and WAC13077). These isolates were obtained from the culture collection at the Department of Agriculture and Food Western Australia. Flag leaves of individuals from both populations and parental genotypes were inoculated at Feekes stage 10.0 to 10.3 . Immediately following inoculation, each plot was enclosed in a humidity chamber consisting of a plastic bag misted internally with water, secured with a PVC ring $(15 \mathrm{~cm}$ high and $30 \mathrm{~cm}$ in diameter) at the base of the plot, and shaded from direct sunlight with a shade cloth bag (84 to $90 \%$ cover factor). Humidity chambers were removed $48 \mathrm{~h}$ after inoculation.

Percent leaf area diseased for the P9819RB1 population was assessed on flag leaves at $240^{\circ} \mathrm{C}$ thermal days (sum of average daily temperatures) in 2004 and $280^{\circ} \mathrm{C}$ in 2008 , whereas the 05 Y001 population was assessed at $220^{\circ} \mathrm{C}$ in both 2007 and 2008. Rating scales for leaf infection were based on a percentage scale from $0 \%$ (highly resistant) to $100 \%$ (highly susceptible) as previously described (15). Disease ratings on flag leaf were scored for three to six individual plants and an average for each plot was calculated and used for analysis.

Measurements of plant height were taken as the distance from the soil surface to the top of the spike (awns excluded) for each plot. Heading date in 2004, 2005, and 2007 was measured as days to full head emergence from date of planting and, in 2008, as days to awn peep.

Statistical analysis. All statistical analysis was done using Genstat version 8.1. Pearson's correlation coefficient was estimated between plant height, heading date, and flag leaf disease scores. Significant differences between genotypes for all traits were assessed using one-way analysis of variance (ANOVA) in randomized blocks. Broad-sense heritability estimates were calculated using the formula $H^{2}=\sigma_{\mathrm{g}}{ }^{2} / \sigma_{\mathrm{g}}{ }^{2}+\sigma_{\mathrm{e}}{ }^{2} / r$, where $\sigma_{\mathrm{g}}{ }^{2}$ and $\sigma_{\mathrm{e}}{ }^{2}$ are the genotypic and error variance, respectively, and $r$ is the number of replications.

QTL analysis. The mean disease scores for flag leaf disease scores, plant height, and heading date were used for composite interval mapping (CIM). CIM model one of Windows QTL Cartographer version 2.5 (29) was used with conditional settings of 10-cM control intervals, five control markers (determined by QTL Cartographer to account for the genetic background variation), and forward regression (33). Experiment-wise critical thresholds for significance of potential QTL for each year were determined using CIM to conduct permutation tests as previously described (7). Highly significant $(P=0.01)$ and significant $(P=$ $0.05)$ QTL thresholds were calculated from 1,000 permutations.

\section{RESULTS}

Phenotypic analysis for flag leaf disease, plant height, and morphology. Highly significant difference $(t$ test, $P<0.01)$ was observed between parental means of EGA Blanco and Millewa, with the former showing consistently lower flag leaf disease scores in 2007 and 2008 (Table 1). Although a significant difference ( $t$ test, $P<0.05$ ) was observed between means of P92201D5 and P91193D1 in 2004, the lower flag leaf score varied between parents did not show significant difference $(P>0.05)$ in 2005 (Table 1). Both populations P9819RB1 and 05Y001 showed continuous distribution in each year (data not shown), indicating polygenic inheritance, and ANOVA showed highly significant difference between individual genotypes for flag leaf disease in each year (Table 1).

There was a significant difference between mean values for EGA Blanco and Millewa and DH genotypes with the lowest and highest flag leaf score in 2007, respectively. A significant difference between Millewa and the most susceptible DH individual was observed in 2008. Broad-sense heritability $\left(\mathrm{H}^{2}\right)$ for flag leaf resistance in the P9819RB1 and 05Y001 populations were moderate to high across successive years, at 0.53 to 0.70 , respectively (Table 1), indicating that the genotypic value of each homozygous individual is suitable for QTL analysis.

Highly significant differences between mean values of parents and individuals with extreme phenotypes were observed in successive years for both plant height and heading date in each population (Table 1). Individuals for each population showed a continuous distribution for plant height and heading date in each year (data not shown) and ANOVA showed highly significant differences between genotypes. Ranges for broad-sense heritabil- 
ity for plant height and heading date were moderate to high (Table 1).

Highly significant but moderate correlation between consecutive years was observed for flag leaf disease scores for individuals in each population (Tables 2 and 3). Although correlations between years for plant height scores and heading date scores were generally large and highly significant, $r$ values between flag leaf scores, plant height, and heading date for each year were generally low to moderate but significant (Tables 2 and 3 ).

QTL analysis for flag leaf disease, plant height, and heading date. QTL analysis identified a number of different chromosomal regions controlling flag leaf resistance in P9819RB1 and 05Y001 populations. In the former population, one highly significant QTL on the distal end of the short arm of chromosome $2 \mathrm{~A}$ was detected in each successive year and accounted for 11.2 to $21.8 \%$ of the phenotypic variation (Table 4). Resistance at this QTL was contributed by the P92201D5 allele, and details of marker interval and $\log$ of the likelihood ration (LOD) scores are provided in Table 4. Disease evaluation in 2004 identified the QTL between marker loci $w P t-2448$ and $w P t-7056$ whereas QSnl05.daw-2A spanned an overlapping region between markers gwm614a and $w$ Pt-9432 based on 2005 disease scores (Table 4; Fig. 1). No other significant QTL for flag leaf resistance were detected in this population in either year.

The 05Y001 population detected two QTL for flag leaf resistance on chromosomes $1 \mathrm{~B}$ and 5B in 2007 and 2008. The highly significant QTL QSnl07.daw-1B and QSnl08.daw-1B colocated within a marker interval of $14.8 \mathrm{cM}$ between $w P t-2988$ and $g w m 264$ and accounted for $\approx 16 \%$ of the phenotypic variation (Fig. 1; Table 4). A second QTL for flag leaf resistance was detected on the long arm of chromosome $5 \mathrm{~B}$, accounting for 8 to $14 \%$ of the total phenotypic variation. The QTL detected using mean data values from phenotypic evaluation in 2007 spanned a marker interval between $w P t-4628$ and $w P t-1733$ where the LOD

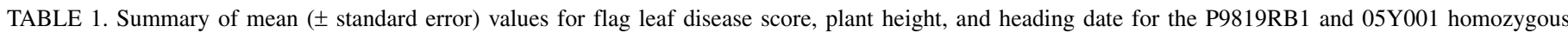
populations $^{\mathrm{a}}$

\begin{tabular}{|c|c|c|c|c|c|c|}
\hline Population $^{\mathrm{b}}$ & $\begin{array}{c}\text { Flag leaf } \\
\text { (\% infection) }\end{array}$ & $\begin{array}{l}\text { Height } \\
\text { (cm) }\end{array}$ & $\begin{array}{l}\text { Heading date } \\
\quad \text { (days) }\end{array}$ & $\begin{array}{c}\text { Flag leaf } \\
\text { (\% infection) }\end{array}$ & $\begin{array}{l}\text { Height } \\
(\mathrm{cm})\end{array}$ & $\begin{array}{l}\text { Heading date } \\
\text { (days) }\end{array}$ \\
\hline \multicolumn{7}{|l|}{ P9819RB1 } \\
\hline P92201D5 & $42.9( \pm 5.7)$ & $84.2( \pm 2.4)$ & $92.3( \pm 4.6)$ & $33.8( \pm 5.1)$ & $64.2( \pm 2.0)$ & $74.3( \pm 1.3)$ \\
\hline P91193D1 & $25.8( \pm 2.2)$ & $79.0( \pm 14.58)$ & $113.5( \pm 4.3)$ & $37.7( \pm 4.3)$ & $70.0( \pm 2.9)$ & $80.0( \pm 0.0)$ \\
\hline \multicolumn{7}{|l|}{ Population } \\
\hline Minimum & $7.7( \pm 2.7)$ & $60.0( \pm 4.1)$ & $78.3( \pm 1.7)$ & $15.6( \pm 7.9)$ & $50.8( \pm 3.0)$ & $67.0( \pm 0.0)$ \\
\hline Maximum & $90.4( \pm 0.4)$ & $108.3( \pm 3.1)$ & $144.0( \pm 0.0)$ & $77.8( \pm 1.4)$ & $112.5( \pm 5.1)$ & $150.0( \pm 0.0)$ \\
\hline Mean & $41.3( \pm 0.8)$ & $79.8( \pm 0.4)$ & $105.5( \pm 0.7)$ & $41.5( \pm 0.7)$ & $79.8( \pm 0.36)$ & $95.3( \pm 14.6)$ \\
\hline $\operatorname{LSD}(P<0.05)$ & 16.4 & 6.6 & 9.6 & 10.1 & 6.2 & 8.5 \\
\hline $\mathrm{CV} \%$ & 23.7 & 2.0 & 1.7 & 15.4 & 8.9 & 6.9 \\
\hline $\operatorname{ANOVA}(P)$ & $<0.01$ & $<0.01$ & $<0.01$ & $<0.01$ & $<0.01$ & $<0.01$ \\
\hline$H^{2}$ & 0.70 & 0.66 & 0.79 & 0.64 & 0.75 & 0.93 \\
\hline \multicolumn{7}{|l|}{$05 \mathrm{Y} 001$} \\
\hline EGA Blanco & $35.0( \pm 6.3)$ & $79.4( \pm 1.8)$ & $91.7( \pm 0.9)$ & $27.0( \pm 1.8)$ & $80.3( \pm 1.0)$ & $92.0( \pm 0.0)$ \\
\hline Millewa & $56.1( \pm 1.3)$ & $79.1( \pm 1.5)$ & $88.0( \pm 1.4)$ & $54.7( \pm 2.8)$ & $75.8( \pm 1.3)$ & $88.4( \pm 1.1)$ \\
\hline \multicolumn{7}{|l|}{ Population } \\
\hline Minimum & $22.1( \pm 1.1)$ & $61.6( \pm 2.1)$ & $74.5( \pm 1.5)$ & $24.7( \pm 2.0)$ & $62.5( \pm 2.1)$ & $77.7( \pm 1.7)$ \\
\hline Maximum & $64.1( \pm 3.7)$ & $95.0( \pm 1.3)$ & $99.0( \pm 0.0)$ & $56.5( \pm 9.2)$ & $91.6( \pm 1.7)$ & $101.7( \pm 1.7)$ \\
\hline Mean & $42.7( \pm 1.5)$ & $78.0( \pm 0.1)$ & $86.9( \pm 0.4)$ & $37.2( \pm 0.4)$ & $76.1( \pm 0.2)$ & $89.6( \pm 0.2)$ \\
\hline $\operatorname{LSD}(P<0.05)$ & 8.0 & 4.8 & 3.7 & 7.1 & 4.0 & 3.4 \\
\hline $\mathrm{CV} \%$ & 14.2 & 6.6 & 3.3 & 14.5 & 5.6 & 2.8 \\
\hline $\operatorname{ANOVA}(P)$ & $<0.01$ & $<0.01$ & $<0.01$ & $<0.01$ & $<0.01$ & $<0.01$ \\
\hline$H^{2}$ & 0.61 & 0.56 & 0.77 & 0.53 & 0.73 & 0.78 \\
\hline
\end{tabular}

${ }^{a}$ For population P9819RB1, first and second years were 2004 and 2005; and, for 05Y001, first and second years were 2007 and 2008, respectively.

${ }^{\mathrm{b}} \mathrm{LSD}=$ least significant difference, $\mathrm{CV}=$ coefficient of variation, ANOVA = analysis of variance, and $H^{2}=$ broad-sense heritability.

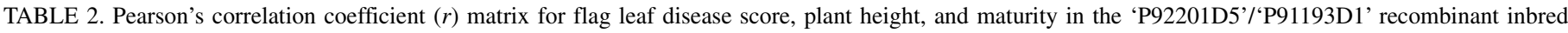
population (P9819RB1) ${ }^{\mathrm{a}}$

\begin{tabular}{|c|c|c|c|c|c|c|}
\hline Trait & Flag leaf 2004 & Heading date 2004 & Height 2004 & Flag leaf 2005 & Heading date 2005 & Height 2005 \\
\hline Flag leaf 2004 & & $\ldots$ & $\ldots$ & $\ldots$ & $\ldots$ & $\ldots$ \\
\hline Heading date 2004 & $0.150 * *$ & $\ldots$ & $\ldots$ & $\ldots$ & $\ldots$ & $\ldots$ \\
\hline Height 2004 & $0.182 * *$ & $0.337 * * *$ & $\ldots$ & $\ldots$ & $\ldots$ & $\ldots$ \\
\hline Flag leaf 2005 & $0.65 * * *$ & N/A & N/A & $\ldots$ & $\ldots$ & $\ldots$ \\
\hline Heading date 2005 & N/A & $0.861 * * *$ & N/A & $0.523 * * *$ & $\ldots$ & $\ldots$ \\
\hline Height 2005 & N/A & N/A & $0.675 * * *$ & $0.411 * * *$ & $0.768 * * *$ & $\ldots$ \\
\hline
\end{tabular}

a Symbols: $* *=$ significant $(P<0.05), * * *=$ highly significant $(P<0.001)$, and N/A = not applicable.

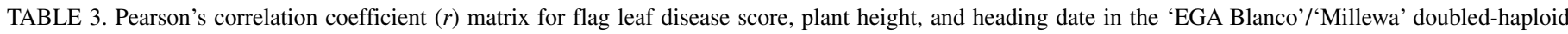
population $(05 \mathrm{Y} 001)^{\mathrm{a}}$

\begin{tabular}{|c|c|c|c|c|c|c|}
\hline Trait & Flag leaf 2007 & Heading date 2007 & Height 2007 & Flag leaf 2008 & Heading date 2008 & Height 2008 \\
\hline Flag leaf 2007 & $\ldots$ & $\ldots$ & $\ldots$ & $\ldots$ & $\ldots$ & $\ldots$ \\
\hline Heading date 2007 & $-0.041^{*}$ & $\ldots$ & $\ldots$ & $\ldots$ & $\ldots$ & $\ldots$ \\
\hline Height 2007 & $-0.189 * * *$ & $0.361 * * *$ & $\ldots$ & $\ldots$ & $\ldots$ & $\ldots$ \\
\hline Flag leaf 2008 & $0.381 * * *$ & N/A & N/A & $\ldots$ & $\ldots$ & $\ldots$ \\
\hline Heading date 2008 & N/A & $0.868 * * *$ & N/A & $-0.189 * *$ & $\ldots$ & $\ldots$ \\
\hline Height 2008 & N/A & N/A & $0.744 * * *$ & $-0.301 * * *$ & $0.405 * * *$ & $\ldots$ \\
\hline
\end{tabular}

a Symbols: $*=$ not significant $(P>0.05), * *=$ significant $(P<0.05)$, *** $=$ highly significant $(P<0.001)$, and N/A= not applicable. 
score of 8.8 peaked at markers $f c p 001$ and $f c p 620$ (Table 4; Fig. 2 ). Interestingly, $f c p 001$ and $f c p 620$ are reported to be tightly linked markers to the Tsn locus (34) and shown to have highly significant association and positioned centrally within QSnl07.daw$5 B$. However, analysis of flag leaf resistance using mean values from 2008 disease evaluation detected a highly significant but overlapping locus, QSnl08.daw-5B, between marker loci fcp620 and wPt9598 (Table 4; Fig. 2). Qsnl08.daw-5B peaked with an LOD score of 4.4 at marker locus $w P t 1733$ and $\approx 18 \mathrm{cM}$ from $f c p 001$ and $f c p 620$. The markers tightly linked to Tsn1, $f c p 001$, and $f c p 620$ showed no significant $(P>0.05)$ association with QSnl08.daw-5B (Table 4; Fig. 2).

The analysis of mean data for plant height and heading date identified a number of QTL for each year. A locus for heading date was detected near QSnl04.daw-2A and QSnl05.daw-2A, with small effects accounting for $<16 \%$ of the phenotypic variation (Table 4). A comparison of genetic map positions of QTL for heading date identified some overlap with QTL for flag leaf resistance on chromosome $2 \mathrm{~A}$ in 2004 but only in a portion of the 4.5-cM barc124b-gwm512 interval (Fig. 1). Therefore, flag leaf disease and heading date were linked and the small correlation between phenotypic values (Table 2) confirmed that QTL for disease resistance is unlikely to be a pleiotropic effect. The remaining QTL for heading date were detected on other chromosomes but accounted for smaller proportion of the total phenotypic variation (Table 4). QTL for plant height in the 9819RB1 population were also detected on chromosomes $2 \mathrm{D}, 4 \mathrm{D}$, and $5 \mathrm{D}$ and each accounted for $\leq 20 \%$ of the phenotypic variation (Table 4).

The analysis of heading date detected QTL co-located on chromosome $5 \mathrm{~B}$ in a similar region for flag leaf resistance (Fig.
2), with the Vrn2 marker locus identified as the major determinant controlling heading date on wheat chromosome 5B (32), positioned within only $Q S n l . d a w-5 B$ (Fig. 2). The weak or absent correlation observed between flag leaf resistance and heading date from individuals of the 05Y001 population (Table 3) confirmed the likelihood of linkage between resistance and heading date loci on chromosome 5B rather than pleiotropy. Other significant QTL for flag leaf resistance and heading date that account for minor portions of the total phenotypic variation are summarized in Table 4. No significant QTL were detected for plant height in the 05Y001 population in 2007 or 2008.

\section{DISCUSSION}

The identification of alternative sources of genetic variation and corresponding QTL provides an opportunity to manipulate chromosomal regions for desirable trait variation in plant improvement. This study identified a new QTL for flag leaf resistance to SNB on chromosomes $1 \mathrm{BS}$ in a spring wheat mapping population 05Y001 (contributed by EGA Blanco). Previous reports have identified a QTL with seedling and flag leaf resistance to SNB and a toxin-sensitive locus, Snn1, between markers KsuD14 and $m w g 938$ and distal to $1 \mathrm{BS}-9$ breakpoint $(13,16,17)$. Markers $w P t$ 8948, wPt-1116, and gwm264 associated with QSnl04.daw-1B and $Q S n l 05 . d a w-1 B$ in this study have been assigned proximal to the $1 \mathrm{BS}-10$ breakpoint and within the centromeric region of $1 \mathrm{BS}$ (11). Therefore, it is reasonable to assume that QSnl04.daw-1B and $Q S n l 05 . d a w-1 B$ are different from those previously reported on $1 \mathrm{BS}(13,16,17)$ based on comparative chromosomal map position for markers associated with QTL. If toxin insensitivity is associated with QTL on 1BS in this study, then a gene or genes

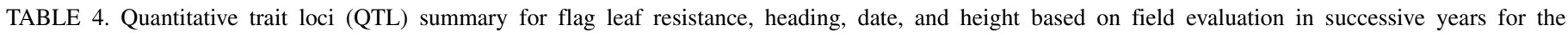
'P9819RB1' and '05Y001' homozygous populations

\begin{tabular}{|c|c|c|c|c|c|c|c|}
\hline \multirow[b]{2}{*}{ Population, trait ${ }^{\mathrm{a}}$} & \multirow[b]{2}{*}{ Chromosome } & \multirow[b]{2}{*}{ Marker interval } & \multirow[b]{2}{*}{ Distance $(\mathrm{cM})^{\mathrm{b}}$} & \multicolumn{2}{|c|}{ Composite interval mapping } & \multirow[b]{2}{*}{ Additive $^{\mathrm{e}}$} & \multirow[b]{2}{*}{$R^{2}$} \\
\hline & & & & LOD threshold ${ }^{\mathrm{c}}$ & Maximum LOD ${ }^{\mathrm{d}}$ & & \\
\hline \multicolumn{8}{|l|}{ P9819RB1 } \\
\hline Flag leaf resistance (2004) & QSnl.daw-2A & wPt2448-wPt7056 & 24.4 & 2.8 & $6.4(w P t 9432)$ & 5.25 & 0.112 \\
\hline \multirow[t]{3}{*}{ Heading date (2004) } & QHd.daw- $2 A$ & gwm512-wPt7056 & 27.4 & 2.8 & $5.5(w P t 1112)$ & 7.83 & 0.162 \\
\hline & QHd.daw-2D & barc230-wPt6003 & 8.9 & 2.2 & $2.5(\operatorname{barc} 230)$ & 4.55 & 0.054 \\
\hline & QHd.daw- $5 A$ & gwm415-gwm186 & 12.2 & 2.3 & $2.9(\mathrm{gwm} 186)$ & 5.63 & 0.084 \\
\hline Height (2004) & QHt.daw-5D & cfd102b-gwm371 & 25.4 & 1.9 & $11.2(c f d 102)$ & 5.39 & 0.204 \\
\hline Flag leaf resistance (2005) & QSnl.daw-2A & gwm614a-wPt9432 & 29.5 & 2.7 & $13.3($ barc 124$)$ & 3.91 & 0.218 \\
\hline \multirow[t]{3}{*}{ Heading date (2005) } & $\widetilde{Q H d} \cdot d a w-2 A$ & wPt1657-wPt7626 & 19.7 & 3.2 & $4.0(w P t 7056)$ & 6.85 & 0.072 \\
\hline & QHd.daw-2D & barc230-wPt6003 & 12.2 & 2.4 & $3.3(w P t 6003)$ & 6.95 & 0.074 \\
\hline & QHd.daw-4D & wmc331-barc217 & 5.0 & 2.4 & $2.4(\operatorname{barc} 217)$ & 6.70 & 0.069 \\
\hline \multirow[t]{3}{*}{ Height (2005) } & QHt.daw-2D & barc124a-wPt6003 & 13.5 & 2.3 & $3.8(w P t 6003)$ & 3.85 & 0.085 \\
\hline & QHt.daw-4D & wmc331-barc217 & 5.1 & 2.4 & $2.5(\operatorname{barc} 217)$ & 6.72 & 0.069 \\
\hline & QHt.daw-5D & cfd102b-gwm 371 & 8.7 & 2.2 & $2.7(c f d 102)$ & 3.45 & 0.054 \\
\hline \multicolumn{8}{|l|}{$05 Y 001$} \\
\hline \multirow[t]{3}{*}{ Flag leaf resistance (2007) } & QSnl.daw-1B & wPt8949-gwm264 & 8.4 & 2.6 & $10.8(w P t 8949)$ & 3.16 & 0.158 \\
\hline & QSnl.daw-4B & barc0163-wPt0391 & 29.6 & 2.4 & $5.1(w m c 349)$ & 2.31 & 0.082 \\
\hline & QSnl.daw-5B & wPt4628-wPt1733 & 32.2 & 2.7 & $8.8(f c p 001)$ & 3.00 & 0.139 \\
\hline \multirow[t]{5}{*}{ Heading date (2007) } & QHd.daw-3A & gwm0002-cfa2193 & 56.0 & 2.6 & $4.2(w m c 264)$ & 1.37 & 0.059 \\
\hline & QHd.daw-4A & wmc0258-gwm0162 & 47.8 & 2.7 & 4.3 (barc1047) & -1.47 & 0.068 \\
\hline & $\widetilde{Q H d} \cdot d a w-4 B$ & wmc0657-wmc0249 & 11.1 & 2.3 & $3.0($ barcl63) & 1.15 & 0.040 \\
\hline & QHd.daw- $5 A$ & barc0319-wPt5231 & 24.3 & 2.8 & $3.0(w P t 5231)$ & 0.89 & 0.025 \\
\hline & QHd.daw- $5 B$ & fcp620-wPt9598 & 39.5 & 2.7 & $23.6($ Vrn2) & -3.45 & 0.333 \\
\hline \multirow[t]{2}{*}{ Flag leaf resistance (2008) } & QSnl.daw-1B & wPt8949-wPt2575 & 8.4 & 2.6 & $10.1(w P t 8949)$ & 2.31 & 0.162 \\
\hline & QSnl.daw-5B & fcp620-wPt9598 & 39.5 & 2.7 & $4.4(w P t 1733)$ & 1.72 & 0.080 \\
\hline \multirow[t]{5}{*}{ Heading date (2008) } & QHd.daw-3A & gwm0002-cfa2193 & 56.0 & 2.5 & $5.4(w m c 264)$ & 1.45 & 0.078 \\
\hline & QHd.daw-4A & wmc0258-gwm0162 & 47.8 & 2.6 & $5.0($ barc 1047$)$ & -1.40 & 0.073 \\
\hline & QHd.daw $-4 B$ & wmc0657-barc0163 & 11.5 & 2.4 & $2.6(g w m 149)$ & 0.88 & 0.029 \\
\hline & QHd.daw-5A & barc0319-wPt5231 & 24.3 & 2.6 & $3.7(w P t 5231)$ & 0.71 & 0.017 \\
\hline & QHd.daw-5B & fcp620-wPt9598 & 39.5 & 2.7 & $21.5($ Vrn2) & -2.99 & 0.341 \\
\hline
\end{tabular}

a P9819RB1 = P92201D5/P91193D1 and 05Y001 = EGA Blanco/Millewa.

${ }^{\mathrm{b}}$ Centimorgan (cM) distance above threshold level at $P=0.01$.

${ }^{c}$ Log of the likelihood ration (LOD) threshold at $P=0.01$ determined by permutation testing for 1,000 reiterations.

d Maximum LOD score for QTL peak with nearest marker in parenthesis.

e Positive and negative effects indicate the allele was inherited from the female and male parent, respectively. 
alternative to $S n n l$ may reside in the centromeric region. Further work is required to investigate whether toxins are secreted from the fungal isolates used in this study and interactions with toxin insensitivity loci are associated with QSnl04.daw-1B and QSnl05.daw-1B.

There have been no previous reports of QTL for flag leaf or glume resistance to $\mathrm{SNB}$ on chromosome 2A; therefore, QSnl04.daw-2A and QSnl05.daw-2A identified in the P9819RB1 population represent a unique QTL for flag leaf resistance. Previous reports of seedling QTL have been reported in a similar region on $2 \mathrm{AS}(1,21)$ but the lack of common markers between genetic maps did not allow unambiguous co-location for seedling and flag leaf resistance at this locus. It was expected that QSnl04.daw-2A and QSnl05.daw-2A would reside in the same marker interval; however, analysis using data from successive years showed overlapping QTL. The QTL share a chromosomal region of $\approx 5 \mathrm{cM}$ and, therefore, it is assumed that a single QTL has been detected in the 05Y001 population. We cannot exclude the possibility of multiple linked genes residing on $2 \mathrm{AS}$, and disease evaluation in multi-environments would provide further evidence for either a single or linked QTL at the 2AS locus.

This study identified QTL for flag leaf resistance on the long arm of chromosome 5B in the $05 \mathrm{Y} 001$ population contributed by the EGA Blanco. In previous studies, QTL for flag leaf resistance under field conditions were identified on chromosome 5BL, accounted for $\leq 20 \%$ of the total phenotypic variation in a BR34/Grandin RI line population, and co-located with the Tsn1 locus for sensitivity and insensitivity to the host-specific toxin ToxA (13). In this study, markers $f c p 001$ and $f c p 620$, linked within $0.5 \mathrm{cM}$ of $T s n 1$ (34), were significantly associated with flag leaf resistance on chromosome 5BL in at least one environ- ment. Therefore, it is reasonable to assume that Tsn1-ToxA interactions for toxin insensitivity contribute to flag leaf resistance identified by $Q S n l 07 . d a w-5 B L$ in the $05 Y 001$ population. However, $f c p 001$ and $f c p 620$ did not have a significant association with flag leaf resistance when evaluated in 2008. Therefore, an alternative QTL, QSnl08.daw-5B, linked to Tsn1 was identified in the 05Y001 population. Methods for evaluation of 05Y001 populations were near identical in 2007 and 2008, showing co-location of QTL within a 14.8-cM marker interval on chromosome 1B; therefore, it is unlikely that different QTL positions on 5BL reflect inconsistent disease evaluation between years. Moreover, QTL for seedling resistance have been identified in the same tetraploid wheat mapping RI population in different studies where one appears to be controlled by the $T s n 1$ locus (10) and the other is linked to $T s n l$ (14), providing evidence of linked genes for resistance to SNB residing on chromosome 5BL. The reasons for different QTL on 5BL are unknown but environmental conditions may have favored differences in disease development between successive years, causing distinct host gene responses. Indeed, further work is warranted to study the interaction of disease development with different genes on 5BL that contribute to flag leaf resistance in multi-environments.

Morphological traits can have a profound effect on accurate evaluation of disease resistance and subsequent QTL analysis (26). Therefore, phenotyping methods developed to discriminate pleiotropy from linkage $(25,27)$ were implemented in this study for disease evaluation and QTL analysis. Small correlations were observed between trait values in each year for the 05Y001 population, indicating that phenotyping methodologies were effective in reducing or eliminating pleiotropic effects. The Vrn2 gene identified on chromosome 5BL, accounting for a significant

\section{$2 \mathrm{~A}$}

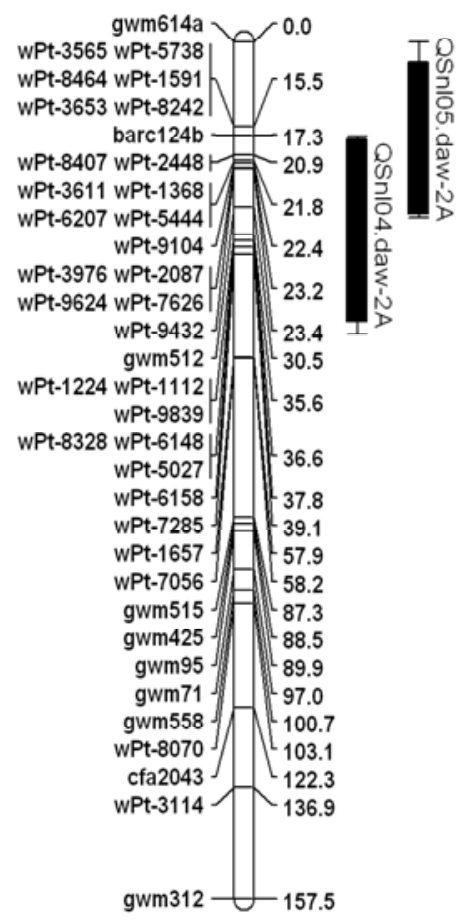

\section{P9819RB1}

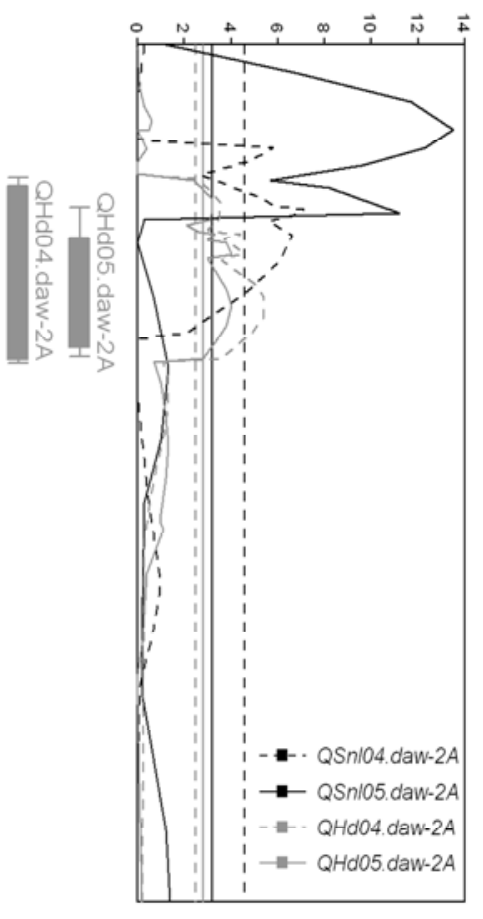

1B

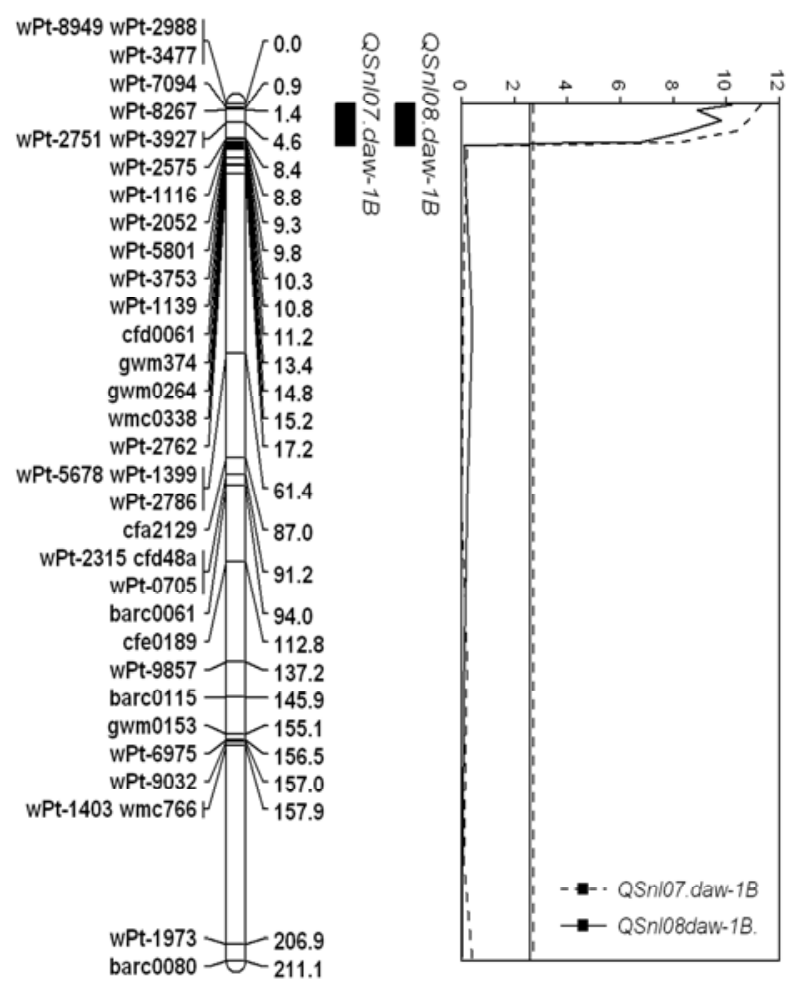

Fig. 1. Quantitative trait loci (QTL) analysis for flag leaf resistance to Stagonospora nodorum in the recombinant inbred line population 'P9819RB1' ('P92201D5'/'P91193D1') and doubled-haploid population '05Y001' ('EGA Blanco'/'Millewa'). QTL on chromosome 2A for flag leaf resistance and heading date from P9819RB1 evaluated in Western Australia in 2004 and 2005 are denoted QSnl04.daw-2A, QSnl05.daw-2A, QHd04.daw-2A, and QHdl05.daw-2A, respectively. QTL on chromosome 1B for flag leaf resistance and heading date from 05Y001 evaluated in Western Australia in 2007 and 2008 are denoted QSnl07.daw-1B, QSnl08.daw-1B, QHd07.daw-1B, and QHdl08.daw-1B, respectively. Black and gray solid bars represent QTL regions. Numbers on the y-axis of the graph represent $\log$ of the likelihood ratio (LOD) scores with highly significant $(P<0.01)$ LOD thresholds for each trait represented by solid and dashed lines. 
proportion of phenotypic variation for heading date (32), including the 05Y001 population in both years, had no significant association with QSnl07.daw-5B or QSnl08.daw-5B, providing further evidence that heading date was unlikely to have pleiotropic effects on flag leaf resistance. Similarly, low to moderate correlation between heading date and disease scores and inconsistent co-location 2A in the P9819RB1 population indicated that flag leaf resistance and heading date QTL are linked. Therefore, methodology used in this study successfully discriminated linkage from pleiotropy between QTL for heading date and flag leaf resistance on chromosomes $2 \mathrm{~A}$ and $5 \mathrm{~B}$.

Generally, wheat breeding programs have not been able to make significant improvements in genetic gain for SNB resistance. This has been largely due to the complex quantitative genetic control of adult plant resistance and effects of environmental interactions on expression of resistance, making phenotypic selection in breeding an arduous task. The key to developing germplasm with adult plant resistance will be to assess which QTL from different sources are consistently detected across multiple and relevant field environments, deploy them in appropriate genetic backgrounds, and identify which QTL combinations provide significant improvements in SNB resistance. The QTL for flag leaf resistance and associated markers identified in this study can be combined with other QTL $(3,13,27,28)$ to develop new germplasm with improved flag leaf resistance to SNB. The use of molecular markers will be an important tool to track and select QTL combinations in germplasm development and commercial breeding. The QTL on chromosome 1B, 2A, and $5 \mathrm{~B}$ identified in this study are obvious choices for increasing genetic gain for SNB resistance.

5B

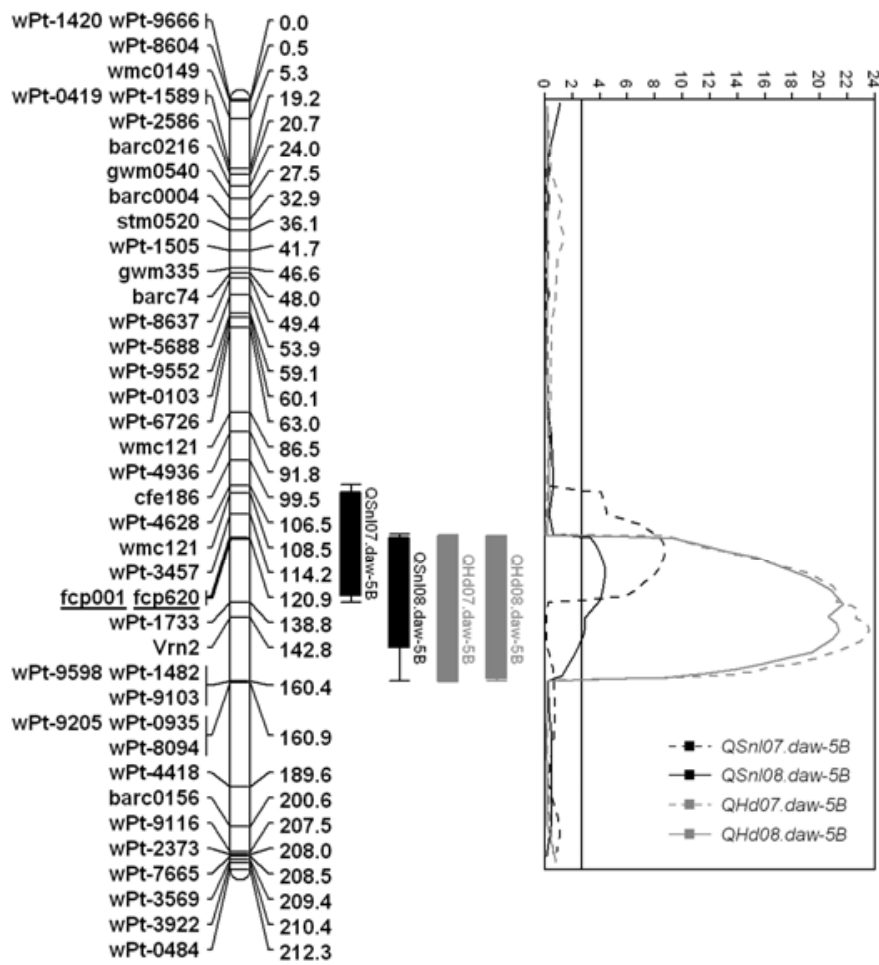

Fig. 2. Quantitative trait loci (QTL) analysis for flag leaf resistance to Stagonospora nodorum on chromosome 5B in the doubled-haploid population 05Y001 ('EGA Blanco'/"Millewa'). QTL for flag leaf resistance and heading date evaluated in Western Australia in 2007 and 2008 are denoted QSnl07.daw-5B, QSnl08.daw-5B, QHd07.daw-5B, and QHdl08.daw-5B, respectively. Markers $f c p 001$ and $f c p 620$, closely linked to Tsn1 (34) are underlined. Black and gray solid bars represent QTL regions. Numbers on the y-axis of the graph represent $\log$ of the likelihood ratio (LOD) scores with highly significant $(P<0.01)$ LOD thresholds for each trait represented by solid and dashed lines.

\section{ACKNOWLEDGMENTS}

This work was supported by the Value Added Wheat Cooperative Research Centre through project 4.5.11 and Grains Research Development Corporation through project DAW126 awarded to M. Francki.

\section{LITERATURE CITED}

1. Abeysekara, N. S., Friesen, T. L., Keller, B., and Faris, J. D. 2009. Identification and characterization of a novel host-toxin interaction in the wheat-Stagonospora nodorum pathosystem. Theor. Appl. Genet. 120:117-126.

2. Adhikari, T. B., Jackson E. W., Gurung, S., Hansen, J. A., and Bonman, J. M. 2011. Association mapping of quantitative resistance to Phaeospharia nodorum in spring wheat landraces from the USDA National Small Grains Collection. Phytopathology 11:1300-1309.

3. Aguilar, V., Stamp, P., Winzeler, M., Winzeler, H., Schachermayr, G., Keller, B., Zanetti, S., and Messmer, M. M. 2005. Inheritance of field resistance to Stagonospora nodorum leaf and glume blotch and correlations with other morphological traits in hexaploid wheat (Triticum aestivum L.). Theor. Appl. Genet. 111:325-336.

4. Arseniuk, E., Czembor P. C., Czaplicki A., Song Q., Cregan, P. B., Hoffman, D. L., and Ueng P. P. 2004. QTL controlling partial resistance to Stagonospora nodorum leaf blotch in winter wheat cultivar Alba. Euphytica 137:225-231.

5. Arseniuk, E., Fried, P. M., Winzeler, H., and Czembor, H. J. 1991. Comparison of resistance of triticale, wheat and spelt to Septoria nodorum blotch at the seedling and adult plant stages. Euphytica 55:43-48.

6. Bostwick, D. E., Ohm, H. W., and Shaner, G. 1993. Inheritance of Septoria glume blotch resistance in wheat. Crop Sci. 33:439-443.

7. Churchill, G. A., and Doerge, R. W. 1994. Empirical threshold values for quantitative trait mapping. Genetics 138:963-971.

8. Czembor, P., Arseniuk, E., Czaplicki, A., Song, Q., Cregan, P. B., and Ueng, P. P. 2003. QTL mapping of partial resistance in winter wheat to Stagonospora nodorum blotch. Genome 46:546-554.

9. Ecker, R., Dinoor, A., and Cahaner, A. 1989. The inheritance of resistance to Septoria glume blotch: I. Common bread wheat, Triticum aestivum. Plant Breed. 102:113-121.

10. Faris, J. D., and Friesen, T. L. 2009. Reevaluation of a tetraploid wheat population indicates that the Tsn1-ToxA interaction is the only factor governing Stagonospora nodorum blotch susceptibility. Phytopathology 99:906-912.

11. Francki, M. G., Walker, E., Crawford, A., Broughton, S., Ohm, H. W., Barclay, I., Wilson, R. E., and McLean, R. 2009. Comparison of genetic and cytogenetic maps of hexaploid wheat (Triticum aestivum L.) using SSR and DArT markers. Mol. Genet. Genom. 281:181-191.

12. Fried, P. M., and Meister, E. 1987. Inheritance of leaf and head resistance of winter wheat to Septoria nodorum in a diallel cross. Phytopathology 77:1371-1375.

13. Friesen, T. L., Chu, C.-G., Liu, Z. H., Xu, S. S., Halley, S., and Faris, J. D. 2009. Host-selective toxins produced by Stagonospora nodorum confer disease susceptibility in adult wheat plants under field conditions. Theor. Appl. Genet. 118:1489-1497.

14. Gonzalelz-Hernandez, J. L., Singh P. K., Mergoum, M., Adhikari, T. B., Kianian, S. F., Simsek, S., and Elias E. M. 2009. A quantitative trait locus on chromosome 5B controls resistance of Triticum turgidum (L.) var. diccocoides to Stagonospora nodorum blotch. Euphytica 166:199-206.

15. James, W. C. 1971. An illustrated series of assessment keys for plant diseases, their preparation and usage. Can. Plant Dis. Surv. 51:39-65.

16. Liu, Z. H., Faris, J. D., Meinhardt, S. W., Ali, S., Rasmussen, J. B., and Friesen, T. L. 2004. Genetic and physical mapping of a gene conditioning sensitivity in wheat to a partially purified host-selective toxin produced by Stagonospora nodorum. Phytopathology 94:1056-1060.

17. Liu, Z. H., Friesen, T. L., Rasmussen, J. B., Ali, S., Meinhardt, S. W., and Faris, J. D. 2004. Quantitative trait loci analysis and mapping of seedling resistance to Stagonospora nodorum leaf blotch in wheat. Phytopathology 94:1061-1067.

18. Mullaney, E. J., Martin J. M., and Scharen, A. L. 1982. Generation mean analysis to identify and partition the components of genetic resistance to Septoria nodorum in wheat. Euphytica 31:539-545.

19. Murray, G. M., and Brennan, J. P. 2009. Estimating disease losses to the Australian wheat industry. Aust. Plant Pathol. 38:558-570.

20. Nelson, L. R., and Gates, C. E. 1982. Genetics of host plant resistance of wheat to Septoria nodorum. Crop Sci. 22:771-773.

21. Paillard, S., Schnurbusch, T., Winzeler, M., Messmer, M., Sourdille, P., Abderhalden, O., Keller, B., and Schachermayr, G. 2003. An integrative genetic linkage map of winter wheat (Triticum aestivum L.). Theor. Appl. Genet. 107:1235-1242.

22. Reszka, E., Song, Q., Arseniuk E., Cregan P. B., and Ueng P. P. The QTL 
controlling partial resistance to Stagonospora nodorum blotch disease in winter Triticale 'Bogo'. Plant Pathol. Bull. 16:161-167.

23. Rufty, R. C. Hebert, T. T., and Murphy, C. F. 1981. Evaluation of resistance to Septoria nodorum in wheat. Plant Dis. 65:406-409.

24. Scharen, A. L., and Krupinsky, J. M. 1978. Detection and manipulation of resistance to Septoria nodorum in wheat. Phytopathology 68:245-248.

25. Schnurbusch, T., Paillard, S., Fossati, D., Messmer, M., Schachermayr, G., Winzeler, M., and Keller, B. 2003. Detection of QTLs for Stagonospora glume blotch resistance in Swiss winter wheat. Theor. Appl. Genet. 107:1226-1234.

26. Scott, P. R., Benedikz, P. W., and Cox, C. J. 1982. A genetic study of the relationship between height, time of ear emergence and resistance to Septoria nodorum in wheat. Plant Pathol. 31:45-60.

27. Shankar, M., Walker E., Golzar, H., Loughman, R., Wilson, R. E., and Francki M. G. 2008. Quantitative trait loci for seedling and adult plant resistance to Stagonospora nodorum in wheat. Phytopathology 98:886-893.

28. Uphaus, J., Walker, E., Shankar, M., Golzar, H., Loughman, R., Francki, M., and Ohm, H. 2007. Quantitative trait loci identified for resistance to Stagonospora glume blotch in wheat in the USA and Australia. Crop Sci. 47:1813-1822.
29. Wang, S., Basten, C. J., Gaffney, P., and Zeng, Z. B. 2005. Windows QTL Cartographer 2.5 user manual. Bioinformatics Research Center, North Carolina State University, Raleigh. Online publication. statgen.ncsu.edu/ qtlcart/WinQTLCart.pdf.

30. Wicki, W., Winzeler, M., Schmid, J. E., Stamp, P., and Messmer, M. 1999. Inheritance of resistance to leaf and glume blotch caused by Septoria nodorum Berk. in winter wheat. Theor. Appl. Genet. 99:1265-1272.

31. Wilkinson, C. A., Murphy, J. P., and Rufty, R. C. 1990. Diallel analysis of components of partial resistance to Septoria nodorum in wheat. Plant Dis. 74:47-50.

32. Yan, L., Loukoianov A., Blechl, A., Tranquilli G., Ramakrishna W., San Miguel P., Bennetzen J. L., Echenique V., and Dubcovsky J. 2004. The wheat VRN2 gene is a flowering repressor down-regulated by vernalization. Science 303:1640-1644.

33. Zeng, Z. B. 1994. Precision mapping of quantitative trait loci. Genetics 136:1457-1468.

34. Zhang, Z., Friesen, T. L., Simons, K. J., Xu, S. S., and Faris, J. D. 2009. Development, identification, and validation of markers for markerassisted selection against Stagonospora nodorum toxin sensitivity genes Tsn1 and Snn2 in wheat. Mol. Breed. 23:35-49. 